\begin{tabular}{ccc}
\hline & International Journal of Engineering \& Technology, $7(2.12)(2018) 141-144$ \\
SPC & International Journal of Engineering \& Technology \\
Website: $w w w . s c i e n c e p u b c o . c o m / i n d e x . p h p / I J E T$ & Research Paper \\
\hline
\end{tabular}

\title{
Development of security camera combined beacon signal for transmission of disaster and crime situation as well as tracking location
}

\author{
Yong Ho Kim ${ }^{1}$, Gul-Won Bang ${ }^{2}$ \\ ${ }^{1}$ Dept. of Self-designed and Open Majors,277Hyodeok-ro, Gwangju University, Nam-guGwangju city, 61743, KOREA \\ ${ }^{2}$ Dept. of Cyber Security \& Police, 277 Hyodeok-ro, Gwangju University, Nam-gu, Gwangju city, 61743, KOREA \\ *Corresponding author E-mail: bgcom@gwangju.ac.kr
}

\begin{abstract}
Background/Objectives: There is the needs for the service to send text message of location to guardian and acquaintance, and police station by waving smartphone quicklyin emergency circumstances that are on the cards at the moment.

Methods/Statistical analysis: Android marshmallow version 6.0.1 in Samsung galaxy S6 smartphone is used to test beacon convergent security camera. Used application is Beacon Finder and test result of address and UUID in beacon is normally generated and found that the values have normal output.

Findings: Development of security camera combined beacon signal for transmission of disaster and crime situation as well as tracking location is development in this study. Design of firmware for beacon signal transmitting device is implemented to achieve the goal. CCTV security camera with beacon signal through circuit design of CCTV and beacon interface is manufactured. Circuit design of beacon signal transmitting device based on Bluetooth 4.0 is implemented to develop an independent device.

Improvements/Applications: Development of security camera combined beacon signal for transmission of disaster and crime situation as well as tracking location is development in this study. Design of firmware for beacon signal transmitting device is implemented to achieve the goal.Foundation technique in the field of home network, USN, and LED lighting control is possible to secure as various technique element for ubiquitous related convergence technology in the field of home electronic appliance with digital information is included
\end{abstract}

Keywords: Security Camera; Beacon; Iot; Disaster Relief; USN; LED.

\section{Introduction}

CCTV plays an important role not only in preventing crime and accidents from happening but in recognizing crime quickly but in taking a prompt and appropriate response such as criminal hunt or protection of victim. In addition to the effect of crime prevention, it is also acting as the fear of crime as well as an arrest of criminals and evidence [1], [2]. Nevertheless, it has disadvantages of sending the victim's critical situation in case of the incident or accident because an integrated control center has a lot of work load to monitor a very wide range of area such as a crime prevention, emergency safety management, an illegal dispose of trash, a forest fire observation, a cultural asset protection, and an illegal parking even though CCTV provides real-time monitoring. In order to solve this problem, CCTV integrated control center can be recognized immediately when a victim presses the alarm bell installed CCTV in case of accident [3], [4]. A little bit of doubt arises as to effectiveness due to victim's inaccessible condition near alarm bell or failing to measure the location as an immediate response is possible to display CCTV screen when the emergency alarm is rang. In order to improve the disadvantage, beacon zone within a $50 \mathrm{~m}$ is formed around CCTV to send text message of one's position to guardian or police office by waving smartphone in case of emergency so as to cope with an immediate danger factor [5], [6].

\section{State of related technology}

\subsection{Domestic situation}

Most company in physical security field comprise small and medium-sized enterprises which arean unlisted company with small business structure according to KISA. Above $90 \%$ of enterprises are classified as a manufacturing company of physical company of physical security product rather than service. About 70 percent of sales in domestic image surveillance device are conducted through export. Samsung TECHWIN Co.,Ltd takes possession of 50 percent of total sales while the rest of them takes passion of IDIS Co., Ltd and C\&B Tech respectively. Wireless connection between IP camera and NVR due to intelligent technology in DVR market of Korea is being transitioned. Physical security enterprises in Korea had the highest percentage of manufacturing camera related products and found that DVR was 17 percentage, IP image device was 13 percentage, Solution was 11 percentage, Access Control was 6.3, percentage, Biometric technology was 6.1 percentage, Peripheral equipment was [5.7] percentage, Engine and chip set was 2.0 percentage, and Alarm and monitoring was [1.7] percentage. As the market in the image security becomes polarization of high price and low price, physical security are driving the need for strengthening competitiveness of high value-added intelligent image surveillance 
such as DVR based on high resolution and face recognition at long range. Image security technology is advancing and improvingtowards intelligent image security technology based on high resolution CCTV and DVD environment while biometric technology is advancing towards biometric technology at long range to increase application of recognition.

Technology field such as CCTV camera, DVR/NVR, fingerprint recognition module, biometric terminal is considered the most advanced in the world while the field of IP camera, intelligent image surveillance, and control has reached 80 percentage of world-class technology [7], [8].

\subsection{State of foreign country}

Multinational corporation such as Japan, Germany, and USA has occupied large-scale market of high priced image surveillance products while emerging country like China had a marked breakthrough in physical security product. Security industry such as Honeywell Security in USA, ADT Security, and Tyco Internationalhave a tendency to strengthen a security network cooperated with communication and broadcasting industry. There are some cooperation such as ADT security, G4S Plc, Global Security Solutions, Protection One, and Reliance Security Group considered as major global cooperation in alarm monitoring market. Major foreign cooperation of image security has been provided the integrated image security solution together with product of CCTV, IP camera, DVR and NVR. Above 90 percentage of solution supply cooperation in existing CCTV and DVR has a plan to provide intelligent image recognition solution in the future. Web camera, network camera, and DVR manufactured by Swedish cooperation, Axis has solid markets and released Axis P1346 that is multi-focused HD TV network camera. Objectivevideo cooperation in USA has mainly provided intelligent video solution and they are going high-tech such as an intelligent function connected with large scaled CMS based on data process technology required for physical security, high-end megapixel network camera, and compression codec [9], [10].

\section{Research development result}

In order to provide the service to send text message of location to guardian and acquaintance by waving smartphone quickly in emergency circumstances that are on the cards at the moment, development of beacon convergent is implemented for the transmission of disaster condition as well as crime condition and position location tracking.

\subsection{Development of beacon signal transmitting device}

Circuit of beacon signal transmitting device based on Bluetooth 4.0 chip is designed and manufactured to develop an independent device. Beacon is a wireless communication device based on Bluetooth to be able to provide various information and service with smart device capable of detecting within close range. It is operated by Bluetooth 4.0 technical base which supports low power Bluetooth. Message and service in the set at identified location is transmitted to smartphone after identifying the location of smartphone through a specific value which is transmitted by beacon terminal. Various information and service are provided when users are passing by or visiting the place of installed beacon. It will be used in various for many purpose like navigation through flow of positioning. CC2541 chip manufactured by Texas Instruments cooperation is selected among various Bluetooth 4.0 chip set to develop beacon signal transmitting device. Block diagram of CC2541 is shown in Figure 1.

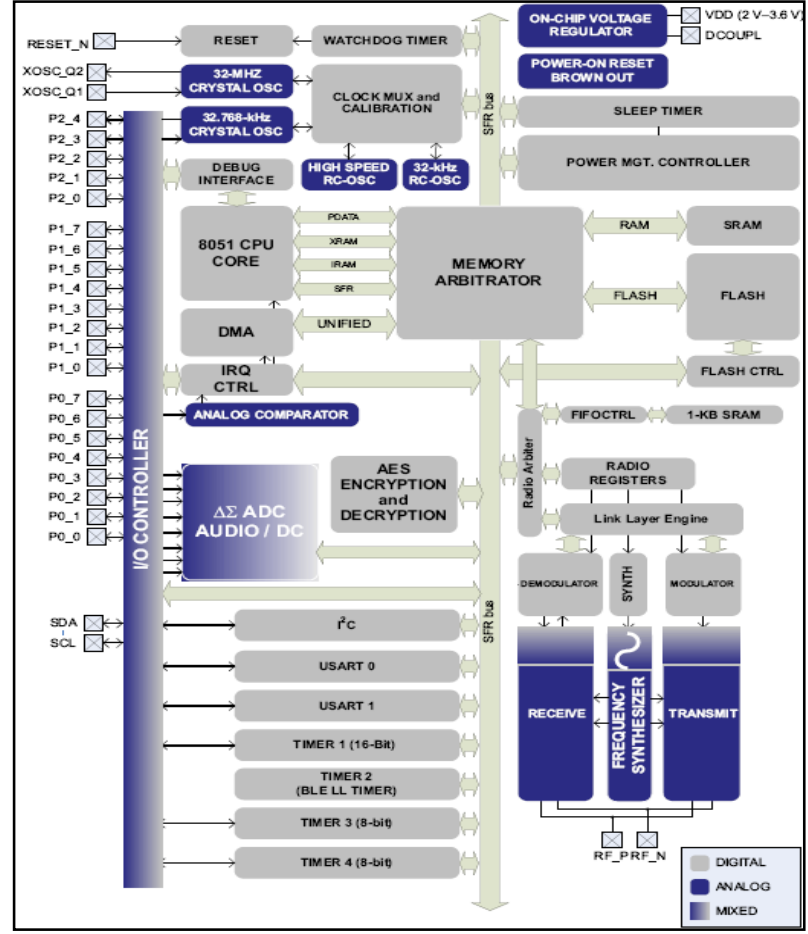

Fig. 1: Block Diagram of CC2541.

Circuit design of beacon signal transmitting device is shown in Figure 2.

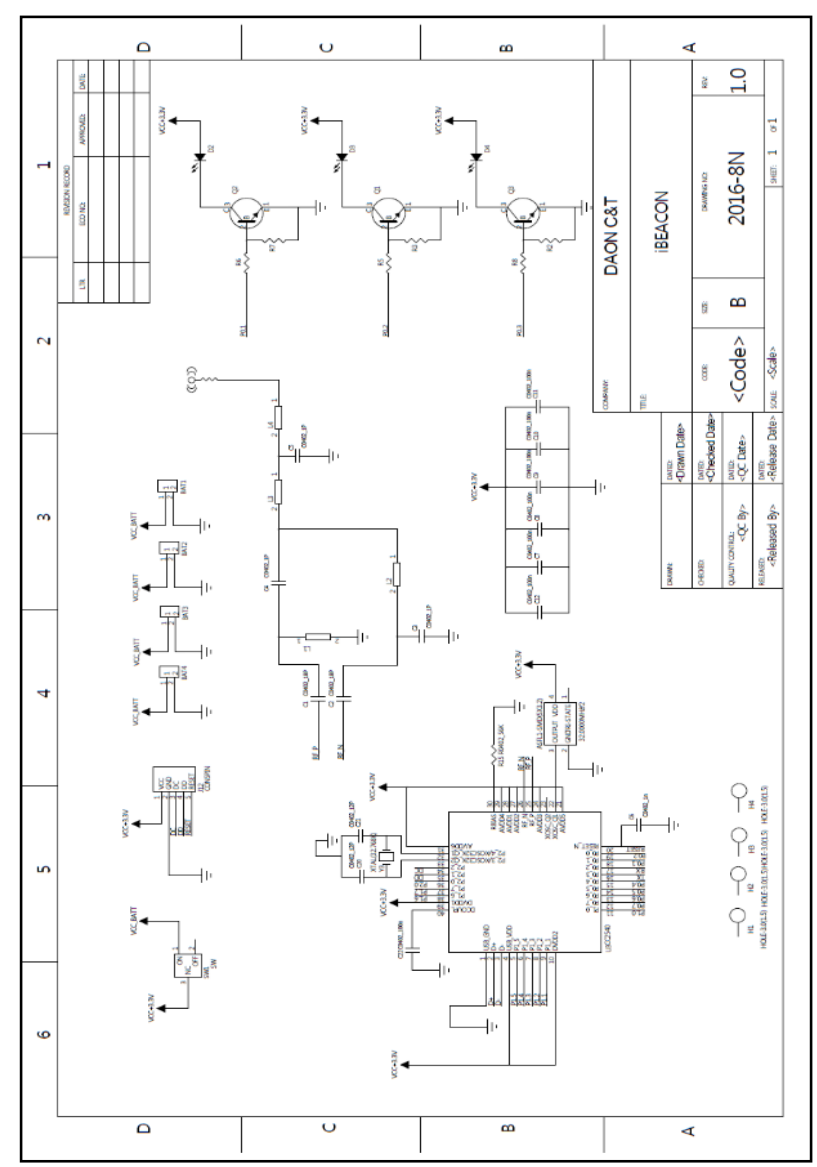

Fig. 2: Circuit Design of Beacon Signal Transmitting Device.

Manufacturing PCB of beacon signal transmitting device and SMT is shown in Figure 3. 


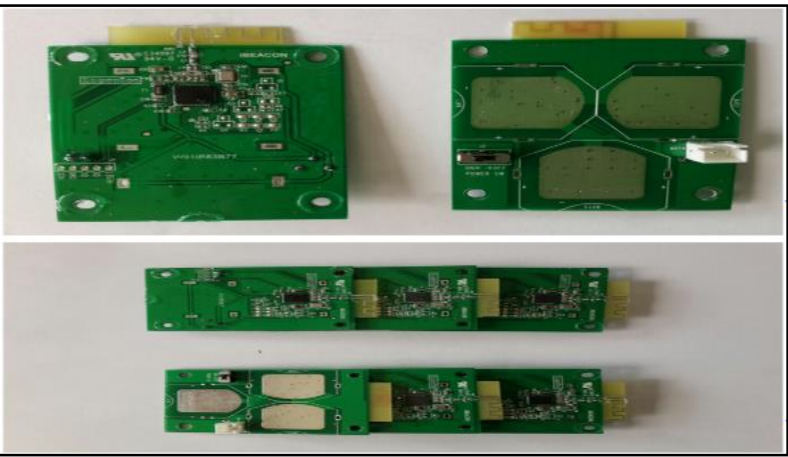

Fig. 3: Picture of PCB in Beacon Signal Transmitter and SMT.

\subsection{Firmware design of beacon signal transmitting de- vice}

AT command is used not only to control but to set Bluetooth module for firmware design in order to change Bluetooth module to beacon module as well as to conducting stable operation. AT command is wirelessly connected MCU, PC or exclusive use app and then AT command is actionable. Applicable response with $\mathrm{OK}+\mathrm{XXX}$ string type in BLE module is given in case of transmitting string with $\mathrm{AT}+\mathrm{XXX}$ type and the value of default setting is as in the following. Baud: 9600, N, 8, 1; Pin code: 000000; Peripheral Role; transmit mode

\subsection{Manufacturing security camera combined beacon signal}

Power supply interface board between CCTV and beacon to recognize a dangerous situation is designed as well as manufactured. 709 model camera with 12 voltage power produced by QRONTEC cooperation is selected to make security camera in this study. Power module for voltage drop is manufactured because beacon signal device uses

\subsection{Voltage power}

ARTwork in consideration of connection between beacon and camera like Figure 4 is designed.
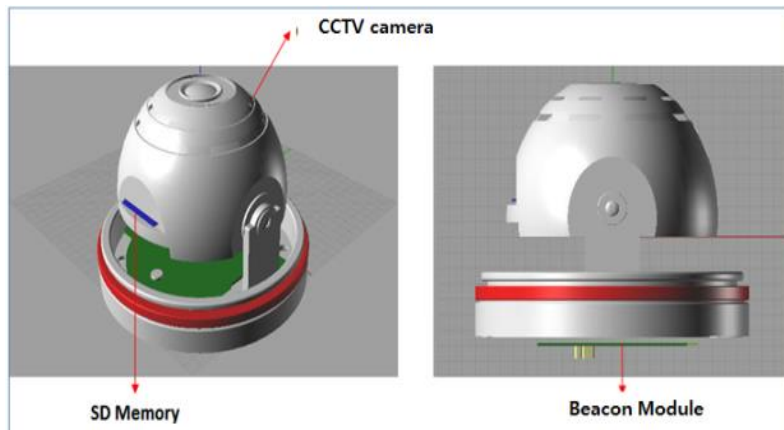

Fig. 4: Artwork Design Considered Connection Between Beacon and Camera.

Design of voltage drop to supply stable power is implemented that input power with 12 voltage drops 5 voltage firstly and then drops

\subsection{Voltage secondly to design}

Interface circuit for beacon combined CCTV. This allows implementation of ARTwork design and manufacturing PCB Circuit design of beacon combined CCTV interface is shown in Figure 5 .

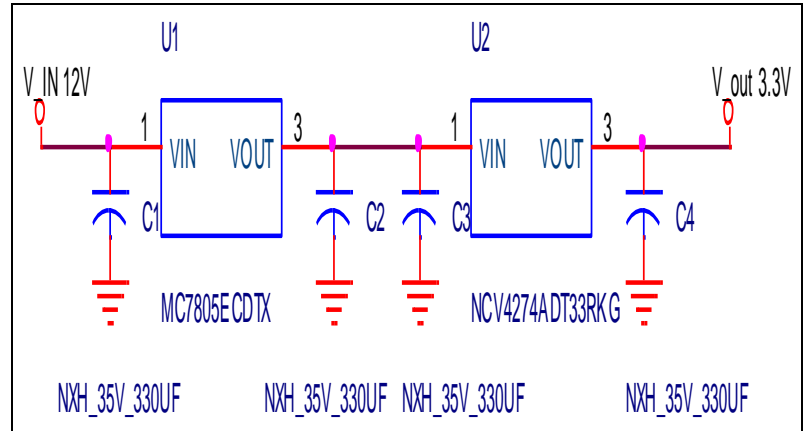

Fig. 5: Interface Circuit Design of Beacon Combined CCTV.

MC7805ECDTX is a regulator manufactured by Fairchild Semiconductor cooperation which has 12 voltage input and 1 ampere output. NCV427ADT33RKG manufactured by On Semiconductor cooperation is a regulator with

\subsection{Volt output}

Camera size is surveyed on the spot to direct connect the camera in order to manufacture ARTwork of interface circuit as well as PCB for beacon combined CCTV. This allows ARTwork to design. PCB of camera interface circuit is shown in Figure 6.

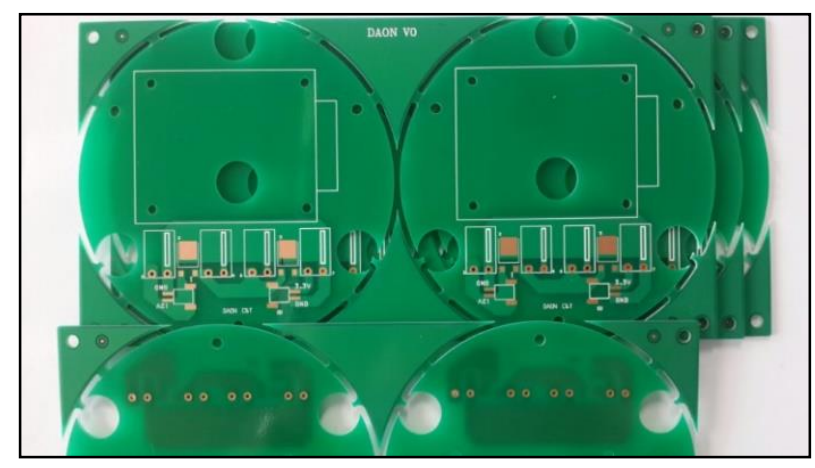

Fig. 6: Camera Interface Circuit PCB.

Camera cover case used LK-790 produced by QRONTEC cooperation is used for only indoor and design of UV coating camera cover case is implemented due to variation of color by ultraviolet rays in case of installation at outside. Drawing of actual survey in camera cover is shown in figure 7

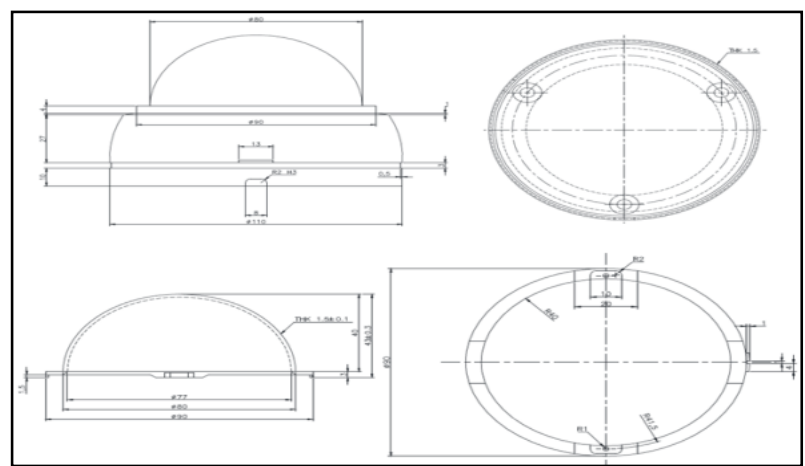

Fig. 7: Actual Survey Drawing of Camera Cover.

\subsection{Voltage}

output through input terminal of motion as well as of sensor input has been identified according to not only the results of statement of the cooperation but the analysis of LK-790 camera module. Power supply design of beacon combined security camera has changed. Design change of power supply is shown in Figure 8. Fabrication result of beacon combined security camera is shown in Figure 9. 


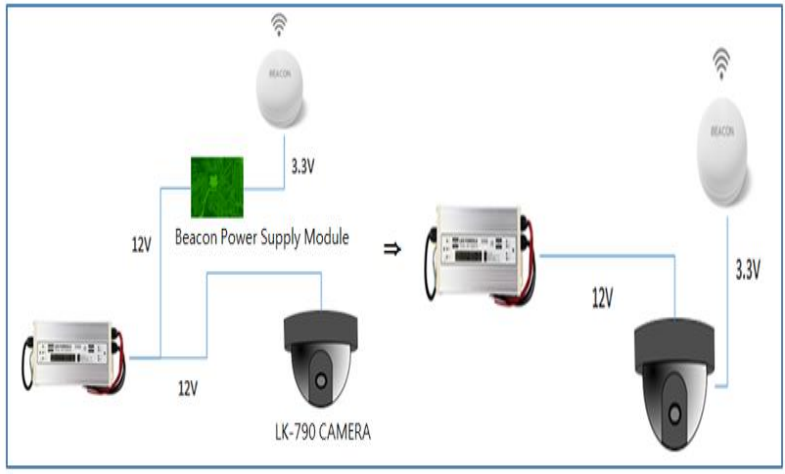

Fig 8: Design Change Concept Drawing of Power Supply.

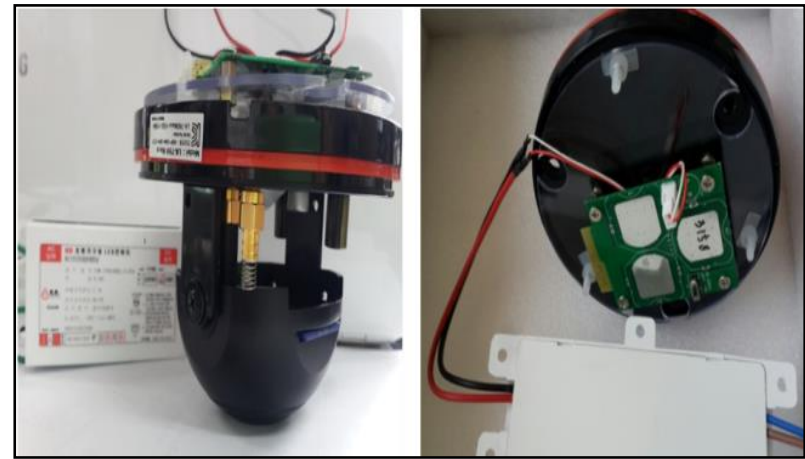

Fig. 9: Manufacturing Beacon Combined Security Camera.

Android marshmallow version 6.0.1 in Samsung galaxy S6 smartphone is used to test beacon combined security camera and used application is BeaconFinder. The result is shown in Figure 10 Test result found that Beacon and Address was normally generated and value of Tx was also normally generated

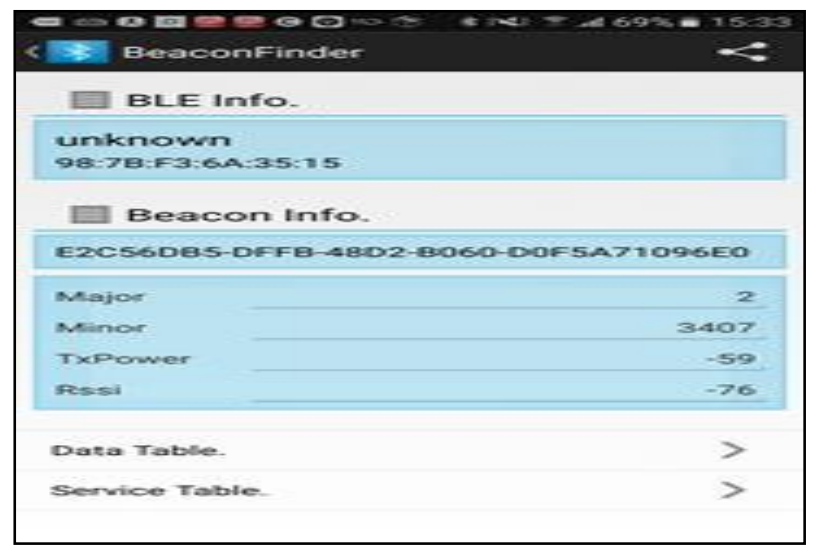

Fig. 10: Test of Beacon Combined Security Camera.

\subsection{Voltage}

Design of voltage drop to supply stable power is implemented thatinput power with 12 voltage drops 5 voltage firstly and then dropsvoltage secondly to design interface circuit for beacon combinedCCTV. This allows implementation of ARTwork design and manu-facturing PCB. Development of beacon signal transmitting device as well as its design of firmware and manufacturing beacon com-bined camera are implemented in this study as a final result.

\section{Conclusion}

In order to provide the service to send text message of location to guardian and acquaintance by waving smartphone quickly in emergency circumstances that are on the cards at the moment, development of beacon combined security camera is implemented for the transmission of disaster condition as well as crime condition and position location tracking. CC2541 Bluetooth chip manufactured by Text Instrument is implemented. This allows ARTwork design and manufacturing PCB. AT command has to be set by serial communication not only to operate but to set embedded Bluetooth and Major, Minor and signal generation period is also set. Camera LK790 model by QRONTEC cooperation is selected to make a security camera in this study and 12 voltage power is used. Power module is manufactured to drop voltage because beacon signal device uses

\section{Acknowledgment}

This Study was conducted by research funds from Gwangju University in 2018, Korea

\section{References}

[1] Kirsch, T.D. , Perrin, P. , Burkle, F.M. , Canny, W. , Purdin, S. , Lin, W. , Sauer, L. , Requirements for Independent Community-Based Quality Assessment and Accountability Practices in Humanitarian Assistance and Disaster Relief Activities, PREHOSPITAL AND DISASTER MEDICINE. 2012, 27(3), pp. 280-285.

[2] Jobe, K., Disaster relief in post-earthquake Haiti: Unintended consequences of humanitarian volunteerism,TRAVEL MEDICINE AND INFECTIOUS DISEASE. 2011, 9(1), pp. 1-5.

[3] Lasowski, R., Linnhoff-Popien, C., Beaconing as a service: a nove service-oriented beaconing strategy for vehicular ad hoc networks, IEEE communications magazine. 2012, 50(10), pp. 98-105.

[4] Sen, W. , Dongbing, G. , Ling, C. , Huosheng, H., Single BeaconBased Localization With Constraints and Unknown Initial Poses, IEEE transactions on industrial electronics. 2016, 63(4), pp. 2229 2241.

[5] Marier, K., Software in the Middle of the New Physical Security Economy Open software providers sit between the camera and everything else. From this unique vantage point, they are closest to enterprise security leaders, Security. 2011, 48(10), pp. 48-59.

[6] Chen, L. , Chen, S. , He, Y.Q. , Wei, J.G. , Dang, J.W., IP Camera Based Network Video Surveillance Mobile Security System, Applied Mechanics and Materials. 2013, 411-414(2), pp. 1505-1509.

[7] Ciuffoletti, A., OCCI-IoT: An API to Deploy and Operate an IoT Infrastructure, IEEE Internet of Things Journal. 2017, 4(5), pp. 13411348.

[8] Chen, Y., The IOT and Smart Logistics Model as the Center of Agricultural Products IOT Port, Advanced Materials Research. 2014 945-949 (5), pp. 3237-3240.

[9] Moon, S. , Choi, E. , Yang, B., Holistic integration based on USN technology for monitoring safety during concrete placement, Automation in construction. 2015, 57(-), pp. 112-119.

[10] Lagrew, J. , Lujan, E. , Nelson, S.C. , Hauff, N.M. , Kaesberg, J.L. , Lambert, M.E. , Riffenburgh, R. , Provencher, M.T. , Douglas, T.D., Pacific Partnership 2010: Anesthesia Support Aboard the USNS Mercy Humanitarian Civic Assistance, Military medicine. 2012, 177(8), 939-946. 